\title{
Bibliometric analysis of global research on the rehabilitation of spinal cord injury in the past two decades
}

This article was published in the following Dove Press journal:

Therapeutics and Clinical Risk Management

\author{
Xiaoxie Liu \\ Nan Liu \\ Mouwang Zhou \\ Yao Lu \\ Fang Li
}

Department of Rehabilitation Medicine, Peking University Third Hospital, Beijing, China
Correspondence: Mouwang Zhou Department of Rehabilitation Medicine, Peking University Third Hospital, 49 North Garden Road, Beijing I00I9I, China

Tel +86 I0 $8226586 \mid$

Fax +86 I0 620I 7700

Email zhoumouwang@163.com
Purpose: We aimed to build a model to qualitatively and quantitatively evaluate publications of research of spinal cord injury rehabilitation from 1997 to 2016.

Methods: Data were obtained from the Web of Science Core Collection on October 6, 2017. We conducted a qualitative and quantitative analysis of publication outputs, journals, authors, institutions, countries, cited references, keywords, and terms by bibliometric methods and bibliometric software packages.

Results: We identified 5,607 publications on rehabilitation of spinal cord injury from 1997 to 2016, and found that the annual publication rate increased with time. The Archives of Physical Medicine and Rehabilitation published the largest number of literature, the most active country was USA, the most active institution was University of Washington, and Post MWM was the leading author. Keyword analysis indicated that life satisfaction, muscle strength, wheelchair training, walking, gait, and others were the hot spots of these research studies, whereas classification, exoskeleton, plasticity, and old adult were research frontiers.

Conclusion: This bibliometric study revealed that research on rehabilitation of spinal cord injury is a well-developed and promising research field. Global scientific research cooperation is close. However, higher quality research is needed. Our findings provide valuable information for researchers to identify better perspectives and develop the future research direction.

Keywords: scientific collaboration network, co-citation network, keywords co-occurrence network, journal analysis, cited reference analysis

\section{Introduction}

Spinal cord injury is a serious disease with high rates of mortality and disability. It deeply affects the quality of life of patients. The annual global incidence is $\sim 10.4-83$ per million inhabitants. ${ }^{1,2}$ Spinal cord injury has placed a considerable burden on the health system. For instance, USA has spent $\sim \$ 9.7$ million a year on spinal cord injuries. What is worrying is that this considerable economic and social burden not only occurs in the acute phase after the injury but also lasts for a long time after the acute phase. The burden lasts even longer for the patients themselves and their families. ${ }^{3,4} \mathrm{With}$ the improvement of medical care technology, the long-term survival rate after spinal cord injury has been significantly improved. ${ }^{5}$ Approximately half of the patients with spinal cord injury develop neurological dysfunction. ${ }^{6}$ Although many neuroprotective strategies have been applied to the treatment of spinal cord injury, none has been identified as standard treatment. ${ }^{7}$ All of these make the importance of rehabilitation after spinal cord injury prominent. 
Providing more resources for basic and clinical research related to rehabilitation of spinal cord injury is crucial for the improvement and development of spinal cord injury rehabilitation. A large number of new technologies and new directions have emerged, such as brain-computer interface, stem cell therapy, and noninvasive brain stimulation, and a great deal of research has been published. Based on bibliometrics, secondary analysis of the knowledge unit characteristics and relationships of published literature can help researchers understand the past and current statuses of spinal cord injury rehabilitation effectively, predict and select future development directions, and design and plan future research. ${ }^{8,9}$ However, up to now, bibliometric studies on rehabilitation of spinal cord injury are rare.

We conducted a bibliometric analysis of the literature related to rehabilitation of spinal cord injury published in the past two decades worldwide. A qualitative, quantitative, and networked in-depth analysis was carried out on the key issues of interest to researchers in this field, such as the overall trend of research, global cooperation in scientific research, research foundation, currently popular topics, and cutting-edge directions.

\section{Materials and methods}

\section{Acquisition of literature}

The first literature search was carried out on June 10, 2017, and updated on August 25th, and the last literature search was conducted on October 6, 2017. The search database was Web of Science (WOS) Core Collection (ie, SCI-EXPANDED, CPCI-S, CCR-EXPANDED, and IC). ${ }^{10}$ The WOS Core Collection is the most commonly used citation database whose data can be processed by a variety of bibliometric analysis software packages. ${ }^{11}$ The search formula is [TOPIC: ("spinal cord injur*") OR TOPIC: ("spinal cord traum*") OR TOPIC: ("spinal injur*") OR TOPIC: ("spinal traum*")] AND [TOPIC: (rehabilitation) OR TOPIC: ("physical medicine") OR TOPIC: ("physical therap*") OR TOPIC: ("occupational therap*")]. The search results over the period from 1997-2016 are refined, and the document types are article, review, proceedings paper, meeting abstract, letter, or editorial material. Two researchers screened the data backto-back. When the two researchers had different opinions, a third researcher made the final decision.

\section{Data processing}

The initial knowledge units were analyzed using the HistCite 12.03.17 software (Thomson Reuters, Toronto, ON, Canada).
The knowledge units analyzed included yearly output, journal, author, institution, country, and document type.

CiteSpace 5.1.R0.SE software (Drexel University, Philadelphia, PA, USA) was used to perform a co-occurrence analysis of knowledge units in the literature, ${ }^{10,12}$ including co-citation network analysis (cited reference and cited journal), research cooperation network analysis (co-author, co-institution, and co-country), and co-word network analysis (keyword and noun phrase). CiteSpace $\mathrm{V}$ is a citation visualization analysis software that can be used to analyze scientific literature from the WOS Core Collection ${ }^{10}$ and presents the structure, pattern, and distribution of scientific knowledge through visualization and network modeling. ${ }^{13}$ The concept of co-citation analysis was proposed by the American information scientist Henry Small in $1973 .{ }^{14}$ This concept refers to the co-cited relationship between the two papers presented in the reference list of the third paper. Scientific research collaborations mean the simultaneous presence of different authors, institutions, or countries in one paper. The basic principle of co-word analysis is to generate the statistics of pairs of words appearing in the same group of documents to measure the relationship between words. In CiteSpace software, keyword analysis uses the original field of the WOS data set, including author keyword (DE) and keyword plus (ID), whereas noun phrase analysis uses the fields extracted from the original field through the part of speech analysis by the software. The extracted fields for this study include author keyword, title, and abstract.

We first calculated and visualized the data to obtain the cooccurrence network. When calculating the data, we selected each year as a time slice and extracted the top 50 objects (references/authors/institutions/countries/keywords/terms) that appeared most frequently or were cited most times in each time slice as nodes. ${ }^{15-17}$ Correlation strength was calculated using the cosine method. After the initial computations, we selected the PATHFINDER algorithm to prune the merged network, crop dense networks, simplify the network, and highlight important structural features. In the visual network formed, the size of a node is related to its importance (times being cited or frequency of occurrence), ${ }^{10}$ whereas the thickness of the connection between nodes is related to the correlation strength of the nodes. We calculated the betweenness centrality of all nodes in the network, and literature with high betweenness centrality is usually the key hub connecting two different areas, also called the turning point. ${ }^{13,15,18,19}$ This metric is used in CiteSpace to gauge the importance of a node in the network structure, and a node with a betweenness centrality $\geq 0.1$ is marked 
with a purple ring..$^{20}$ Then, we performed burst detection on the nodes in each co-occurrence network. When the citation times (or frequency of occurrence) of a certain node in the network, in several years, increase more rapidly than other nodes, a burst is considered to exist, indicating the importance of the node in time..$^{10,15,17}$ CiteSpace uses a red ring to mark the nodes with burst. We conducted citation history analysis and associated node descriptions on the three nodes with the highest betweenness centrality, burst strength, and count in each network.

Finally, we performed cluster analysis on the co-citation network and keyword co-occurrence network and calculated the modularity $(\mathrm{Q})$ and silhouette values of the network. The higher the $\mathrm{Q}$ value of the network, the better the clustering obtained by the network. When $\mathrm{Q}>0.3$, the network community structure is significant. The silhouette value is a measure of the homogeneity of the network. When the silhouette value is $>0.5$, the clustering result is considered reasonable. When the silhouette value is 0.7 , the clustering result has high reliability. In this study, we used the weighted term frequency inverse document frequency $(\mathrm{TF} \times \mathrm{IDF})$ algorithm to extract keywords from the titles of citations as cluster names. ${ }^{18}$

\section{Results}

\section{Analysis of publication outputs}

A total of 5,607 literature were retrieved, including 4,591 articles, 504 reviews, 651 proceedings papers, 81 editorial materials, and 32 meeting abstracts. More than $97 \%$ of the publications were published in English. From 1997 to 2016, the number of literature published in each year showed an increasing trend, although there were fluctuations in some years. The count of annual publications has small peaks in 1998,2002 , and 2008. The rate of growth was relatively slow before 2005 and after 2011, while showing relatively rapid growth from 2005 to 2011 (Figure 1).

\section{Journal analysis}

A total of 978 journal published literature related to the rehabilitation of spinal cord injury in the last 20 years. The top 10 journals that published the largest number of literature are presented in Table 1 . These 10 journals published $52.9 \%$ of the literature in this field. Archives of Physical Medicine and Rehabilitation was the most active journal on rehabilitation of spinal cord injury, followed by Spinal Cord and Journal of Spinal Cord Injury. Of the top 10 journals only one journal had an impact factor (IF) $>5.000$, while four had an IF $>2.000$.

A co-citation network analysis was performed on the cited journals. The co-citation network map and the cluster map which were pruned by PATHFINDER are shown in Figure $2 \mathrm{~A}$ and $\mathrm{B}$, in which the nodes represent the journals of the references. Twenty-five clusters were obtained by cluster analysis. $\mathrm{Q}=0.8388$ indicates a significant community structure of the network. There are nine clusters with a node number $>10$, and their silhouette values are all $>0.7$. The top ranked item by citation counts is also Archives of Physical Medicine and Rehabilitation in cluster \#5 (traumatic spinal cord injury), with citation counts of 4,095, followed by Spinal Cord in cluster \#8 (functional abilities), with citation counts of 3,412 . Using this we found that nine of the top 10 journals that were cited the most by the literature are also the top 10 journals with the largest number of literature.

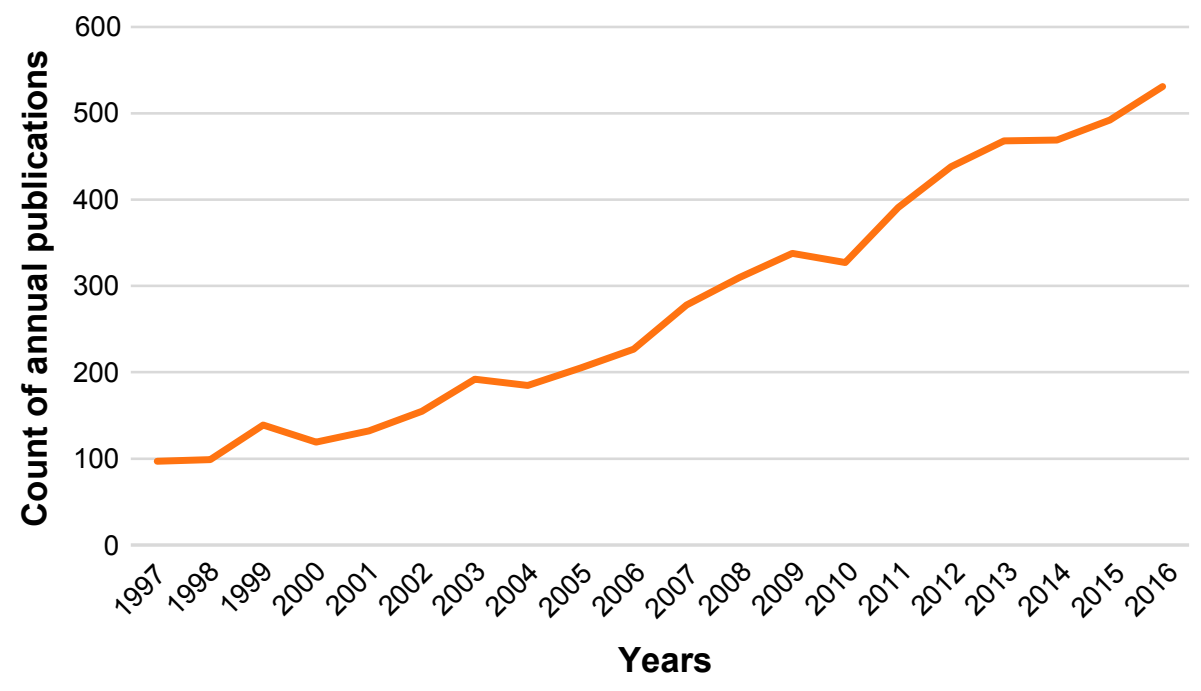

Figure I Trends in the count of scholarly publications related to rehabilitation of spinal cord injury from I997 to 2016. 
Table I The top 10 active journals that published literature on rehabilitation of spinal cord injury research from 1997 to 2016

\begin{tabular}{|c|c|c|c|c|c|}
\hline Ranking & Journal & Frequency & $\begin{array}{l}\text { Times } \\
\text { cited }\end{array}$ & $\begin{array}{l}\text { Times cited } \\
\text { (per article) }\end{array}$ & IF 2016 \\
\hline 1 & Archives of Physical Medicine and Rehabilitation & 1,112 & 30,558 & 27.48 & 3.289 \\
\hline 2 & Spinal Cord & 807 & 15,534 & 19.25 & 1.87 \\
\hline 3 & Journal of Spinal Cord Medicine & 303 & 3,870 & 12.77 & 1.633 \\
\hline 4 & Disability and Rehabilitation & 166 & 2,533 & 15.26 & $\mathrm{I} .804$ \\
\hline 5 & Journal of Rehabilitation Research and Development & 157 & 3,399 & 25.47 & 1.277 \\
\hline 6 & Journal of Rehabilitation Medicine & 107 & I,579 & 14.76 & 1.681 \\
\hline 7 & American Journal of Physical Medicine and Rehabilitation & 104 & 2,030 & 19.52 & $\mathrm{I} .734$ \\
\hline 8 & Neurorehabilitation and Neural Repair & 83 & 3,138 & 37.81 & 4.107 \\
\hline 9 & Journal of Neurotrauma & 66 & $\mathrm{I}, 388$ & 21.03 & 5.19 \\
\hline 10 & Physical Therapy & 61 & $2,07 \mid$ & 33.95 & 2.764 \\
\hline
\end{tabular}

Abbreviation: IF, impact factor.

\section{Scientific collaboration network analysis} Microcosmic collaboration network - author analysis The 5,607 literature on rehabilitation of spinal cord injury were drafted by about 14,000 authors in the last 20 years.
The maximum subnetwork of the co-authorship network and the cluster map are shown in Figure 3A and B, in which the nodes represent the authors of the literature. The network is divided into 169 clusters with an overall $\mathrm{Q}=0.8241$.
A

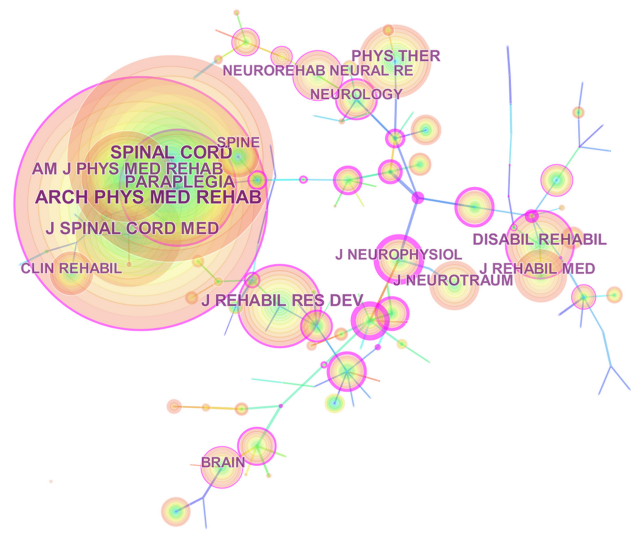

C

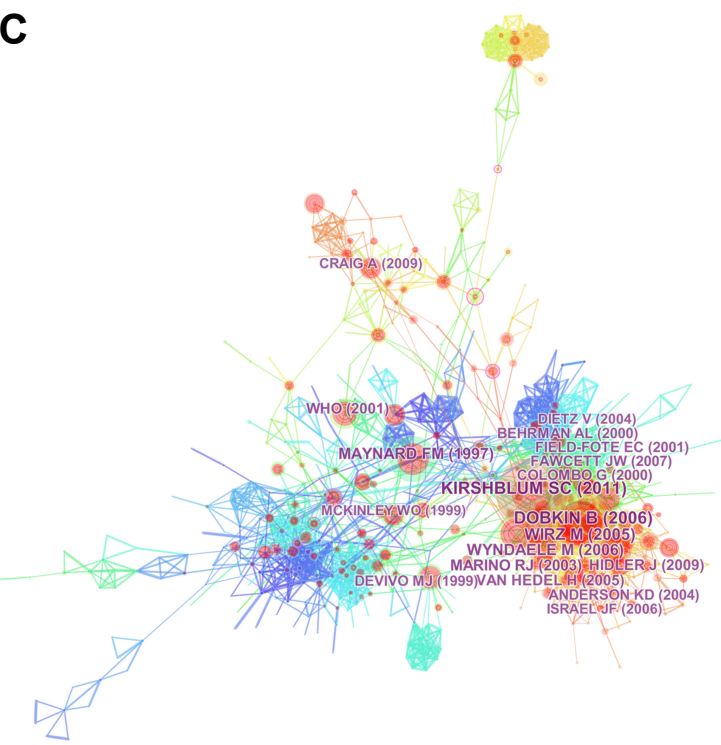

B

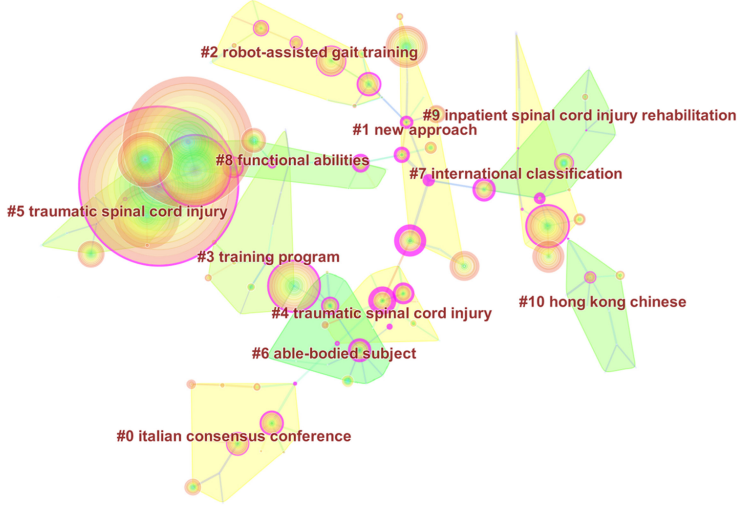

D

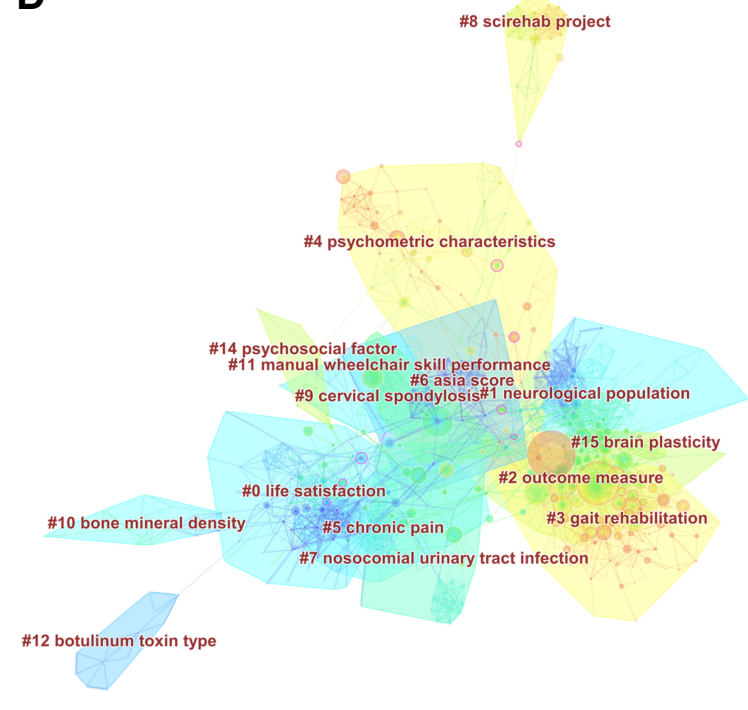

Figure 2 Maps of references cited by the literature on rehabilitation of spinal cord injury from 1997 to 2016 and maps of the cited journals that published the references. (A) Co-citation network map of cited journals. (B) Cluster map of cited journals. (C) Co-citation network map of references. (D) Cluster map of references. The smaller the number, the more nodes the clustering contains.

Abbreviation: SCI Rehab, Spinal Cord Injury Rehabilitation. 
A

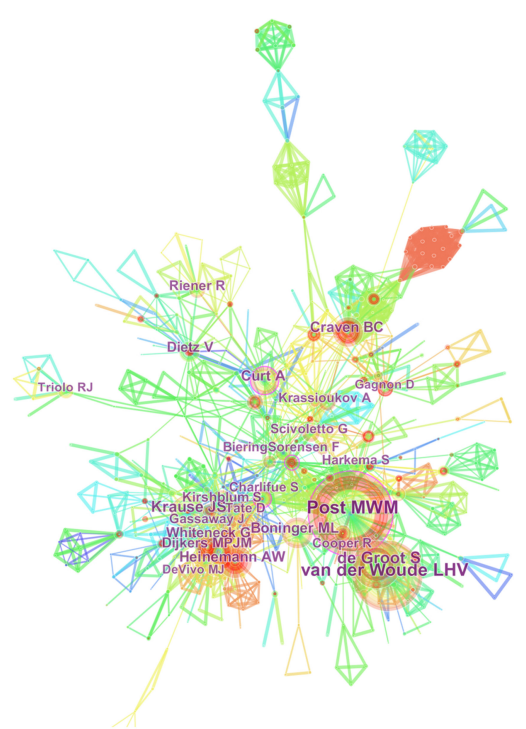

C

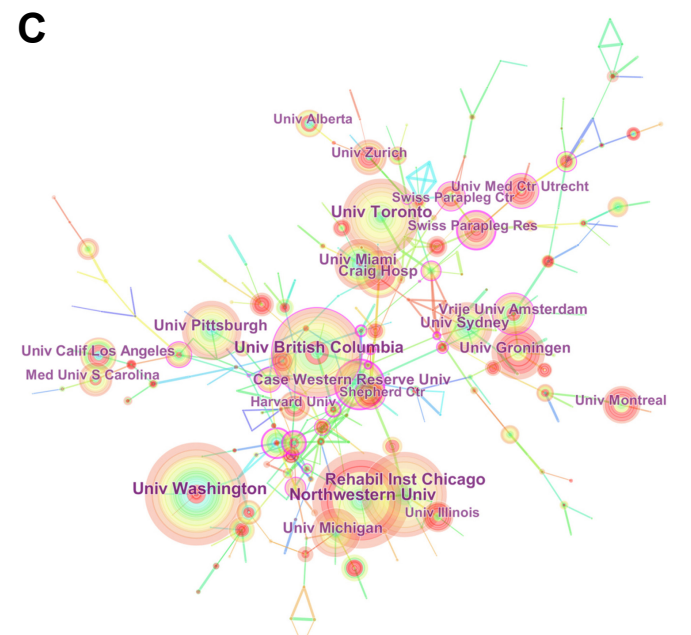

B

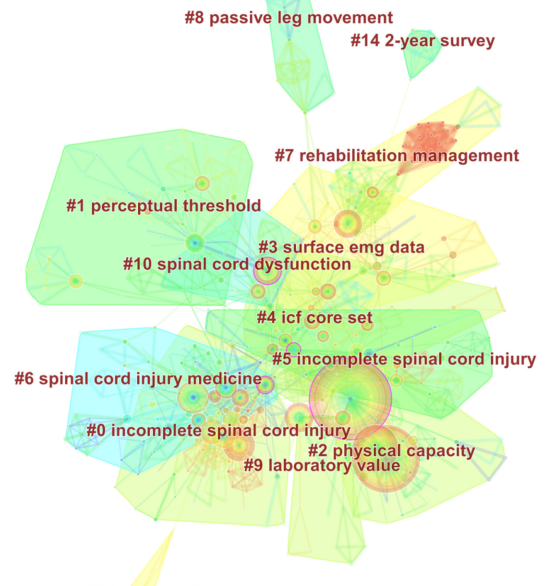

$\# 19$ year post

D

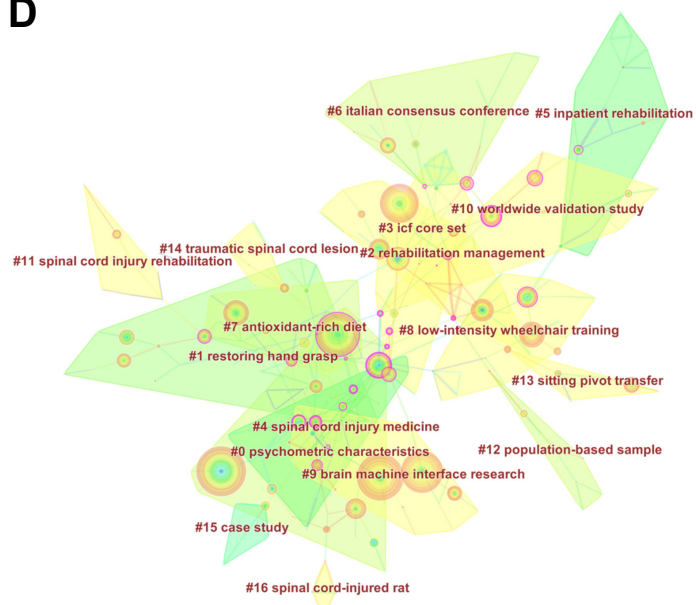

E

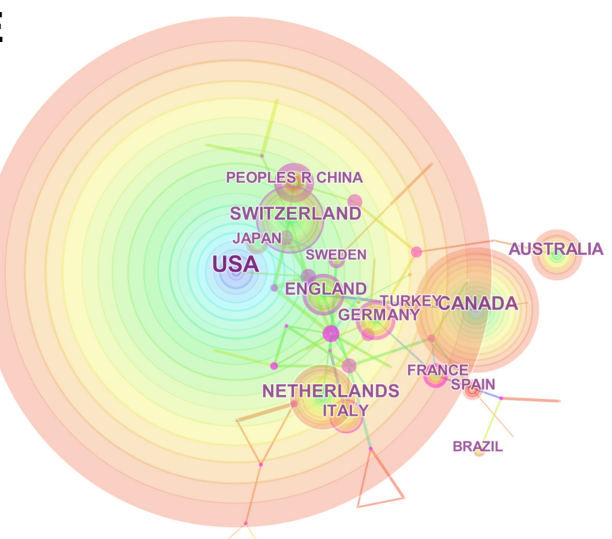

Figure 3 Maps of researchers who published literature on rehabilitation of spinal cord injury from 1997 to 2016. (A) Co-authorship map of authors. (B) Cluster map of authors. (C) Co-authorship map of institutions. (D) Cluster map of institutions. (E) Co-authorship map of countries. The smaller the number, the more nodes the clustering contains.

Abbreviations: EMG, electromyography; ICF, International Classification of Functioning, Disability and Health; Univ, university.

Fourteen of them are with a node number $>10$ and with a silhouette $>0.7$. The top 10 authors who published the largest number of literature are presented in Table 2 along with their institution. The top three ranked authors by citation counts are
Post MWM (131 counts), van der Woude LHV (114 counts), and de Groot S (78 counts) in cluster \#2 (physical capacity), all of whom come from the same scientific research team in University of Groningen. The top three ranked authors 
Table 2 The top 10 active authors who published literature on rehabilitation of spinal cord injury research from 1997 to 2016

\begin{tabular}{lllll}
\hline Ranking & Frequency & Author & Institution & $\begin{array}{l}\text { Times cited } \\
\text { (per article) }\end{array}$ \\
\hline 1 & 131 & Post MWM & University of Groningen & 19.81 \\
2 & 114 & Van der Woude LHV & University of Groningen & 18.56 \\
3 & 78 & De Groot S & University of Groningen & 12.7 \\
4 & 58 & Krause JS & Medical University of South Carolina & 36.82 \\
5 & 52 & Heinemann AW & Northwestern University & 12.05 \\
6 & 51 & Boninger ML & University of Pittsburgh & 21.27 \\
7 & 50 & Craven BC & University of Toronto & 18.10 \\
8 & 49 & Curt A & Balgrist University Hospital & 30.14 \\
9 & 46 & Dijkers MPJM & Wayne State University & 40.55 \\
10 & 44 & Whiteneck G & Craig Hospital & 36.06 \\
\hline
\end{tabular}

by centrality are Charlifue S (Craig Hospital) in cluster \#0, with centrality of 0.16 , Post MWM (centrality $=0.13$ ), and Curt A (Balgrist University Hospital) in cluster \#3 (surface electromyography [EMG] data), with centrality of 0.12 . The citation history of the above authors is presented in Figure 4. In addition, the authors who contributed to a sudden increase in the number of publications in recent years include Craven BC, burst 2009-2016; Heinemann AW, burst 2011-2016; Noonan VK, Hitzig SL, Gagnon D, and Lorenz D, burst 2012-2016; Zafonte R, Post MWM, Amatachaya S, New PW, Morse LR, and Gil-Agudo A, burst 2013-2016; and Duysens J, Krebs J, Vegter RJK, Hornby TG, Bombardier CH, and Pannek J, burst 2014-2016.

\section{Mesoscopic collaboration network - institution analysis}

Literature on rehabilitation of spinal cord injury were published by about 4,200 research institutions in the last 20 years. The maximum subnetwork of the co-authorship network and the cluster map which were pruned by PATHFINDER are shown in Figure $3 \mathrm{C}$ and $\mathrm{D}$. The network is divided into 67 co-citation clusters with an overall $\mathrm{Q}=0.8323$. Eleven clusters had $>10$ nodes, while 10 of them had a silhouette $>0.7$. The top 10 institutions that published the most papers are presented in Table 3. The top three ranked institutions by citation counts are University of Washington (205 counts) in cluster \#0 (psychometric characteristics), Northwestern University (188 counts) in cluster \#9 (brain-machine interface), and University of British Columbia (172 counts) in cluster \#0. The top three ranked institutions by centrality are Craig Hospital (centrality $=0.17$ ) in cluster \#3 (International Classification of Functioning, Disability and Health [ICF] core set), University of British Columbia (centrality $=0.16$ ), and Case Western Reserve University (centrality $=0.11$ ) in cluster \#4 (spinal cord injury medicine). The citation history of the above institutions is presented in Figure 4. The important research partners of University of Washington are University of California, San Francisco, University of Ultah, Schwab Rehabilitation Hospital, and University of British Columbia; University of Texas, Galveston, Icahn School of Medicine at Mount Sinai, VA Puget Sound Health Care System, and Rehabilitation Institute of Chicago with Northwestern University; GF Strong Rehabilitation Centre and Research Laboratory, Rick Hansen Institute, International Collaboration on Repair Discoveries, and Monash University with University of British Columbia; Aurora Hospital, City University of New York, Mount Sinai School of Medicine, Chiang Mai University, Thomas Jefferson University Hospital, Rudolf Magnus Institute of Neuroscience, and Institute of Clinical Outcomes Research with Craig Hospital. In addition, the institutions that were involved in the sudden increase of publications in recent years include Emory University, burst 2010-2016; University of Lucerne, Ohio State University, and Monash University, burst 2011-2016; University of Melbourne, University College London, University Health Network, and University Medical Center Utrecht, burst 2012-2016; University of Montreal, Swiss Paraplegic Centre, University of Groningen, Amsterdam Rehabilitation Research Center, University of Illinois, Delft University of Technology, National Hospital Spinal Cord Injury, University of Maastricht, and University of Loughborough, burst 2013-2016; and University of Sao Paulo, Rutgers New Jersey Medical School, Northwestern University, Tehran University of Medical Sciences, and University of Alabama at Birmingham, burst 2014-2016.

\section{Macroscopic collaboration network - country analysis}

Literature on rehabilitation of spinal cord injury were published by research teams in 84 countries/territories from 


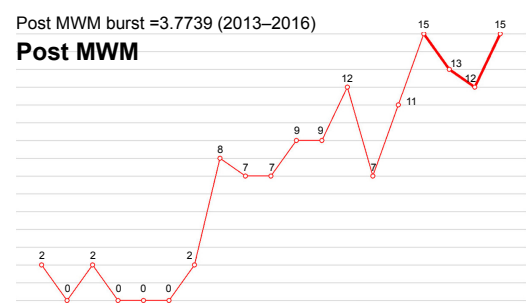

9798990001020304050607080910111213141516

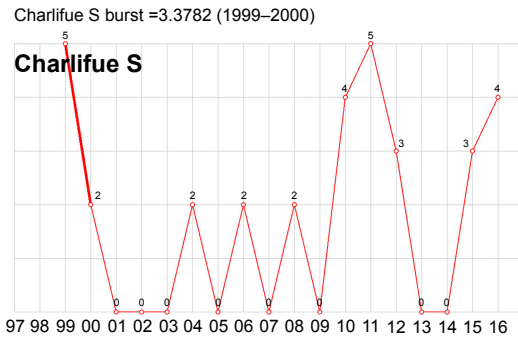

Univ Washington burst $=9.4525$ (1997-2003)

Univ Washington

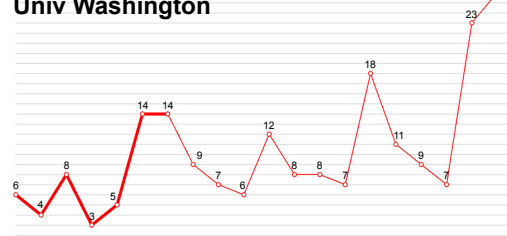

9798990001020304050607080910111213141516

Craig Hosp burst $=8.651(2009-2012)$

Craig Hospital

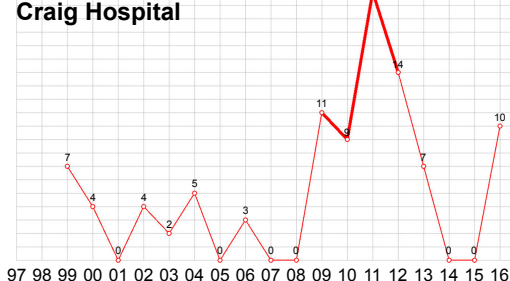

9798990001020304050607080910111213141516

USA

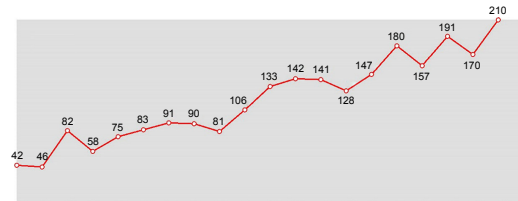

9798990001020304050607080910111213141516

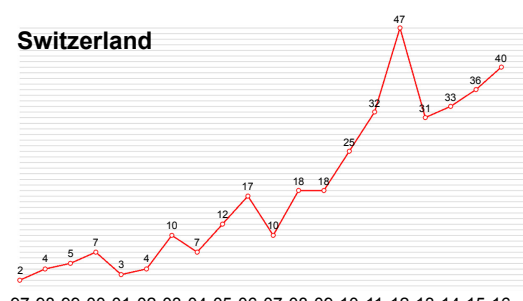

9798990001020304050607080910111213141516

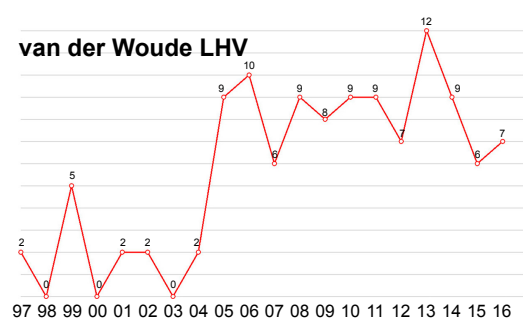

de Groot S burst =7.1545 (2013-2014) de Groot S

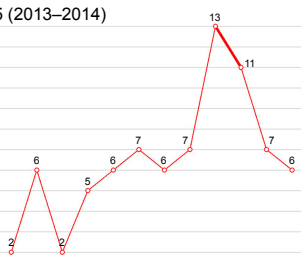

9798990001020304050607080910111213141516

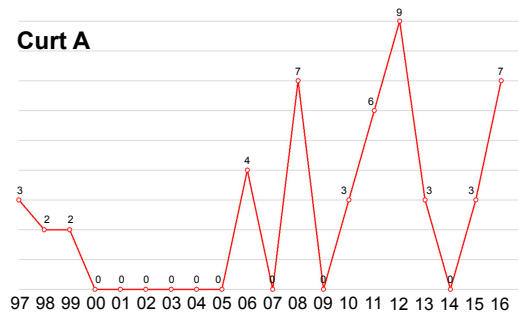

Northwestern Univ burst $=4.3756$ (2014-2016)

Northwestern Univ

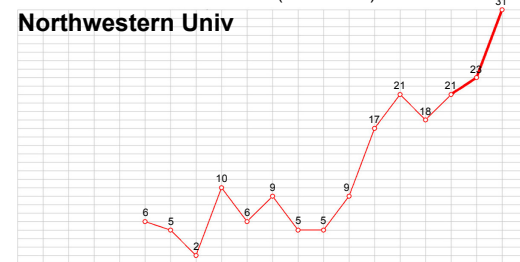

9798990001020304050607080910111213141516
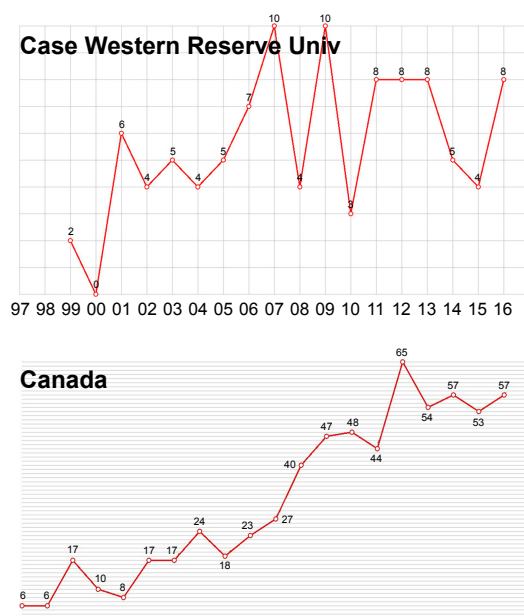

9798990001020304050607080910111213141516

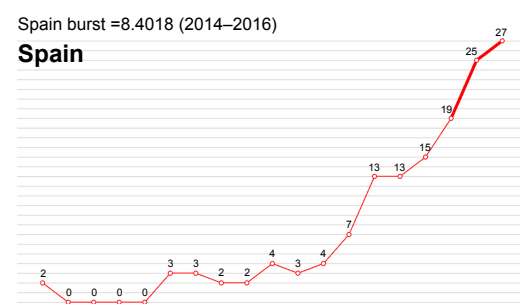

9798990001020304050607080910111213141516
9798990001020304050607080910111213141516
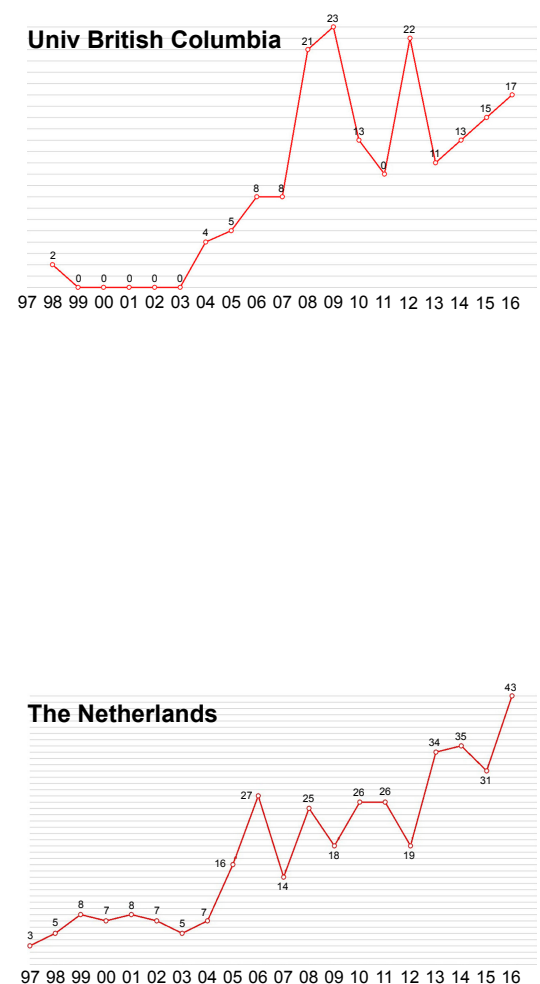

9798990001020304050607080910111213141516

Figure 4 Citation history of the top authors, top institutions, and top countries that published literature on rehabilitation of spinal cord injury from 1997 to 2016. Abbreviation: Univ, University.

1997 to 2016. The co-authorship network map which was pruned by PATHFINDER is shown in Figure 3E. The top 10 countries that published the most papers are presented in Table 3. The top three ranked countries by citation counts are USA (2,347 counts), Canada (638 counts), and the Netherlands (365 counts). The top three ranked countries by centrality are USA (centrality $=0.4$ ), Switzerland (centrality $=0.18$ ), and Spain (centrality $=0.16$ ). The citation 
Table 3 The top 10 active institutions and countries that published literature on rehabilitation of spinal cord injury research from 1997 to 2016

\begin{tabular}{lllll}
\hline Ranking & Frequency & Institution & Frequency & Country \\
\hline 1 & 205 & University of Washington & 2,347 & USA \\
2 & 188 & Northwestern University & 638 & Canada \\
3 & 172 & University of British Columbia & 365 & The Netherlands \\
4 & 164 & Rehabilitation Institute of Chicago & 361 & Switzerland \\
5 & 152 & University of Toronto & 305 & Australia \\
6 & 119 & University of Pittsburgh & 251 & England \\
7 & 106 & University of Miami & 214 & Germany \\
8 & 105 & University of Sydney & 208 & 169 \\
9 & 103 & University of Groningen & Italy \\
10 & 101 & Case Western Reserve University & 160 & Japan \\
\hline
\end{tabular}

history of the above countries is presented in Figure 4. The important research cooperators of USA is South Africa; Turkey with Canada; Scotland and Denmark with the Netherlands; South Africa, Thailand, and Austria had important cooperation with Switzerland; Mexico and Belgium with Spain. There are also some very close teams of multinational research cooperation from the overall network, such as New Zealand-Thailand-South AfricaDenmark team, Denmark-Sweden team, and Israel-Belgium team. In addition, the countries that contributed to a sudden increase in the amount of publications in recent years include China, Thailand, Iran, and Columbia, burst 2013-2016; and Mexico, Egypt, and Spain, burst 2014-2016.

\section{Cited reference analysis}

Citation reference maps consist of references with the highest citation counts and centrality. More than 110,000 references were cited by the literature. The reference co-citation network map and the cluster map are shown in Figure 2C and D. The network is divided into 117 clusters with an overall $\mathrm{Q}=0.7839$. Fourteen of them were with a node number $>10$ and with a silhouette $>0.7$. The largest 10 clusters are presented in Table 4. And, the top 10 references which were cited the most ${ }^{3,21-28}$ are presented in Table 5 .

\section{Keyword and term analysis}

Keywords and terms in the literature on rehabilitation of spinal cord injury were analyzed by a co-occurrence network analysis. The network maps and the cluster maps which were pruned by PATHFINDER are shown in Figure 5. The keyword co-occurrence network is divided into 19 clusters with an overall $\mathrm{Q}=0.7966$. Fourteen of them were with a node number $>10$ and with a silhouette $>0.7$. The largest 10 clusters are presented in Table 6 . We found that the core keywords of almost every cluster appeared for the first time between 1997 and 1998 from the timeline view. Only a very few of them first appeared after 2000, such as the core keywords of cluster \#1 and cluster \#3. The most frequent keywords are quality of life (519 counts), individual (491 counts), recovery (419 counts), paraplegia (410 counts), and tetraplegia (399 counts). The top ranked keywords by centrality are gait (centrality $=0.12$ ), recovery (centrality $=0.11$ ), individual (centrality $=0.10$ ), walking (centrality $=0.08$ ), and functional electrical stimulation (FES, centrality $=0.08$ ). The keywords that appear most often with quality of life are validation, community, adult, outcome, and disability. Individual most often appears with the words cardiac output, paraplegic subject, aerobic power, reciprocating gait orthosis, osteoporosis, and skeletal muscle. Recovery most often appears with the words prognostic value, reflex, walking index, prognosis, motor imagery, speed, weight supported treadmill, motor, and locomotion. Gait most often appears with the words unit, modulation, EMG, robotics, follow-up, therapy, and FES. Walking most often

Table 4 The largest 10 clusters of the references co-citation network

\begin{tabular}{lllll}
\hline Cluster & Size & Silhouette & $\begin{array}{l}\text { Mean } \\
\text { year }\end{array}$ & Label \\
\hline 0 & 105 & 0.823 & 1995 & Life satisfaction \\
1 & 102 & 0.885 & 1998 & $\begin{array}{l}\text { Neurological population } \\
\text { (or central pattern generation) }\end{array}$ \\
2 & 77 & 0.785 & 2005 & $\begin{array}{l}\text { Outcome measure (or cellular } \\
\text { transplant) }\end{array}$ \\
3 & 76 & 0.829 & 2009 & Gait rehabilitation \\
4 & 75 & 0.924 & 2008 & Psychometric characteristics \\
5 & 49 & 0.876 & 1996 & Chronic pain \\
6 & 42 & 0.9 & 1994 & ASIA score \\
7 & 35 & 0.906 & 1999 & Nosocomial urinary tract infection \\
8 & 28 & 0.996 & 2008 & SCl Rehab Project \\
9 & 26 & 0.965 & 1996 & Cervical spondylosis \\
\hline
\end{tabular}

Abbreviations: ASIA, American Spinal Injury Association; SCI Rehab, Spinal Cord Injury Rehabilitation. 
Table 5 The top 10 active references cited by the literature on rehabilitation of spinal cord injury from 1997 to 2016

\begin{tabular}{|c|c|c|c|c|}
\hline Ranking & $\begin{array}{l}\text { Times } \\
\text { cited }\end{array}$ & Reference & Journal information & Cluster \\
\hline I & 131 & $\begin{array}{l}\text { Reference for the } 201 \text { I revision of the International Standards for } \\
\text { Neurological Classification of Spinal Cord Injury }\end{array}$ & J Spinal Cord Med, V34, P547 & 3 \\
\hline 2 & 124 & $\begin{array}{l}\text { Weight-supported treadmill vs over-ground training for walking after } \\
\text { acute incomplete } \mathrm{SCl}^{23}\end{array}$ & Neurology, V66, P484 & 2 \\
\hline 3 & 97 & $\begin{array}{l}\text { Effectiveness of automated locomotor training in patients with chronic } \\
\text { incomplete spinal cord injury: a multicenter trial }{ }^{24}\end{array}$ & Arch Phys Med Rehabil, V86, P672 & 2 \\
\hline 4 & 90 & $\begin{array}{l}\text { International standards for neurological and functional classification of } \\
\text { spinal cord injury. American Spinal Injury Association }{ }^{25}\end{array}$ & Spinal Cord, V35, P266 & 9 \\
\hline 5 & 83 & $\begin{array}{l}\text { Incidence, prevalence and epidemiology of spinal cord injury: what learns a } \\
\text { worldwide literature survey? }\end{array}$ & Spinal Cord, V44, P523 & 2 \\
\hline 6 & 76 & International standards for neurological classification of spinal cord injury ${ }^{26}$ & J Spinal Cord Med, V26, P50 & 2 \\
\hline 7 & 62 & $\begin{array}{l}\text { Assessing walking ability in subjects with spinal cord injury: validity and } \\
\text { reliability of } 3 \text { walking tests }{ }^{27}\end{array}$ & Arch Phys Med Rehabil, V86, PI90 & 2 \\
\hline 8 & 61 & $\begin{array}{l}\text { Multicenter randomized clinical trial evaluating the effectiveness of the } \\
\text { Lokomat in subacute stroke }{ }^{28}\end{array}$ & Neurorehabil Neural Repair, V23, P5 & 3 \\
\hline 9 & 61 & WHO $(200 \mathrm{I})^{41}$ & Not applicable & II \\
\hline 10 & 58 & $\begin{array}{l}\text { Guidelines for the conduct of clinical trials for spinal cord injury as } \\
\text { developed by the ICCP panel: spontaneous recovery after spinal cord } \\
\text { injury and statistical power needed for therapeutic clinical trials }{ }^{29}\end{array}$ & Spinal Cord, V45, PI 90 & 2 \\
\hline
\end{tabular}

Abbreviations: SCI, spinal cord injury; ICCP, International Campaign for Cures of Spinal Cord Injury Paralysis.

appears with the words reciprocating gait orthosis, electric stimulation, cat, and exoskeleton. FES most often appears with the words paraplegics, motor recovery, oxygen uptake, neuroprosthesis, reciprocating gait orthosis, neuromuscular stimulation, ambulation, paraplegic patient, system, muscle, and gait. In addition, the keywords having an increased number of occurrences in recent years include validity and physical activity, burst 2012-2016; randomized control trial and older adult, burst 2013-2016; and classification, exoskeleton, movement, clinical trial, plasticity, and human, burst 2014-2016.

The term co-occurrence network is divided into 31 clusters with an overall $\mathrm{Q}=0.8023$. Fifteen of them were with a node number $>10$ and with a silhouette $>0.7$. The largest 10 clusters are presented in Table 7.

\section{Discussion}

The primary concern of researchers was whether the area under study had potential and whether it was worthwhile to continue investing a great deal of manpower and material resources. Spinal cord injury rehabilitation is a potential research area. In the past 20 years, the number of published papers on spinal cord injury rehabilitation has been increasing year by year, more researchers and funds have been devoted to this field, and more scientific research achievements have been made. According to the annual published volume, spinal cord injury rehabilitation research in the past 20 years can be divided into three stages: the years before 2005 are the initial period and the period when routine problems were solved, 2005-2011 is the period of rapid development and the period when main problems were solved, and after 2011 is the period of slow development. The decline in annual research growth since 2011 indicates, to some extent, a certain development crisis and a certain degree of fatigue in this field of study. Therefore, seeking new and effective technical means, such as artificial intelligence, ${ }^{29,30}$ brain-computer interface, ${ }^{31-35}$ and stem cell therapy, ${ }^{36-40}$ and breakthroughs in the reformation of existing technologies is an urgent task for researchers all over the world.

The research results need to be published in the form of journal articles. At this time, researchers focus their attention on which journals their studies are more likely to be accepted in. In the field of spinal cord injury rehabilitation, the top 10 journals with the largest number of published papers have published more than half $(52.9 \%)$ of the research in this field, and their distribution in journals showed obvious concentration-dispersion. This finding shows that these journals have obvious tendencies in selecting the research content to publish, as well as researchers in this field, in selecting journals. In particular, for the top three journals with the largest number of published papers, that is, Archives of Physical Medicine and Rehabilitation, Spinal Cord, and Journal of Spinal Cord Injury, the academic journals that they represent are more likely to accept studies on spinal cord injury rehabilitation than other journals and have a significant 
A

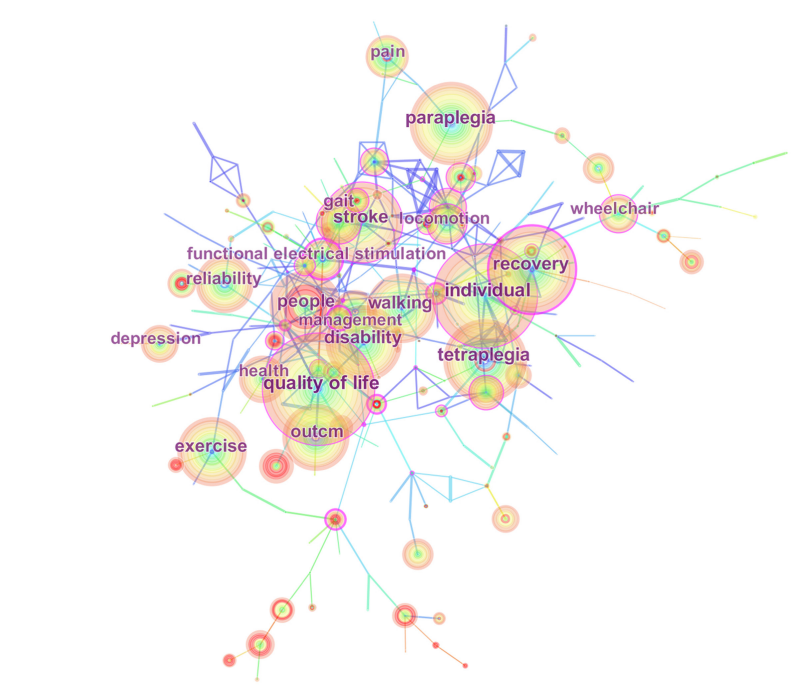

C

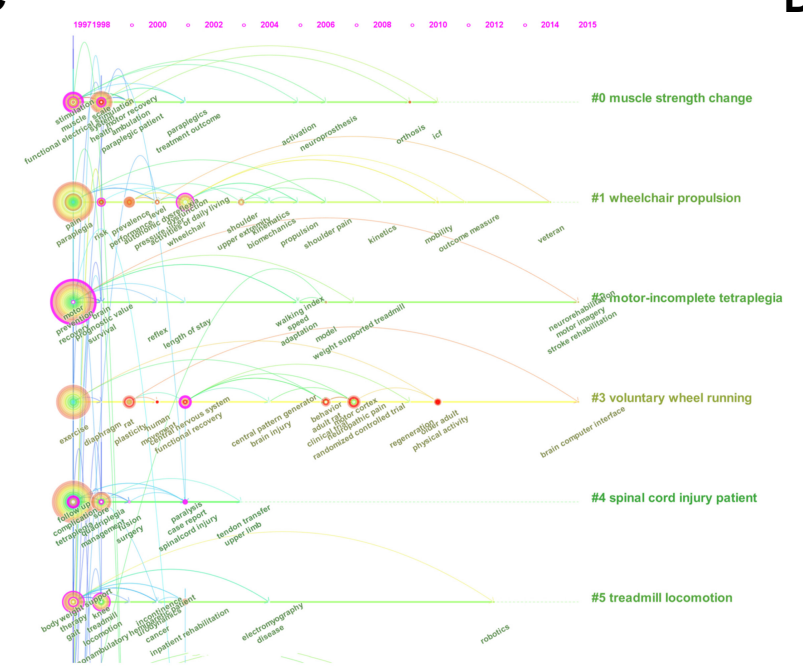

B

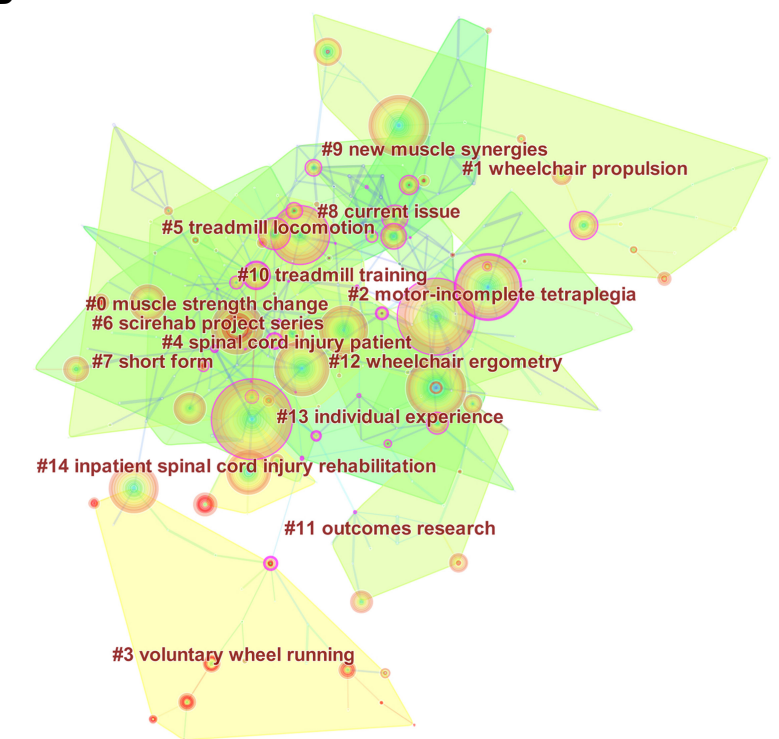

D

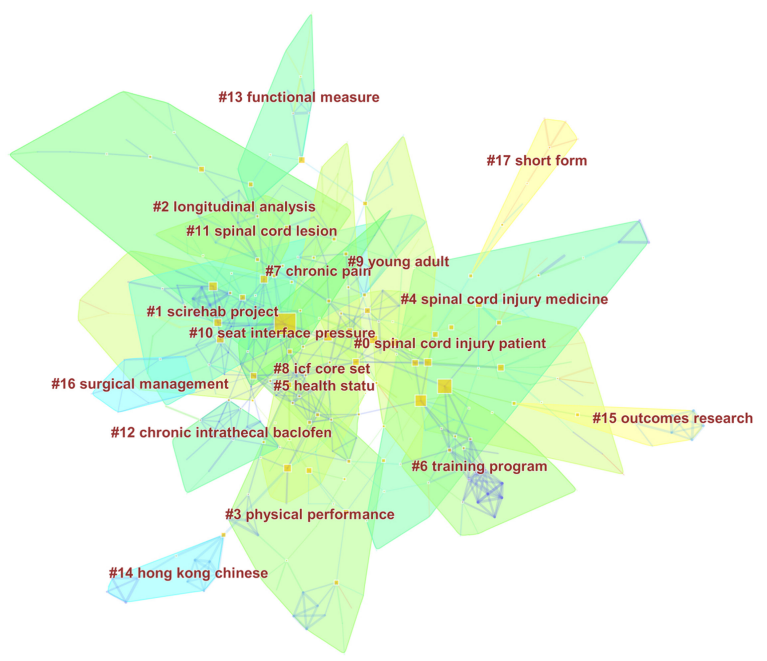

Figure 5 Maps of keyword co-occurrence and term co-occurrence in literature on rehabilitation of spinal cord injury from 1997 to 2016. (A) The keyword co-occurrence network map. (B) The keyword co-occurrence cluster map. (C) The keyword co-occurrence cluster map in timeline view. (D) The term co-occurrence cluster map. The smaller the number, the more nodes the clustering contains.

Abbreviations: SCI Rehab, Spinal Cord Injury Rehabilitation; ICF, International Classification of Functioning, Disability and Health.

impact on the research progress in this field. The Journal Citation Reports IF (2016) of the top 10 journals with the largest number of published papers was low, with only one journal scoring over 5 and only four journals scoring over 2. In addition, there is a $90 \%$ coincidence rate between the top 10 cited journals and top 10 active journals. This may be due to the self-citation of the journals. Moreover, research in this field seldom cited articles from journals with higher IF. All of these findings show that the research level and quality of spinal cord injury rehabilitation still need to be improved. Thus, researchers all over the world should work together and enable high-quality research cooperation on a large scale.

At present, what is the situation of global scientific cooperation in spinal cord injury rehabilitation? Through the co-occurrence network analysis, we observed a close cooperation among researchers all over the world. Different researchers have formed research teams by publishing research together, whereas researchers from different institutions and countries (or territories) have formed cross-agency and cross-national scientific research cooperation through jointly publishing research. As shown in Figure 3, the connection between nodes (authors, institutions, and countries) shows that scientific cooperation exists between the nodes. Apart from several scattered small cooperative teams, most of the researchers and research institutes in the world have formed the largest subnetworks of a certain scale through intricate scientific research cooperation. All of the participating countries (or territories) have formed a close cooperation 
Table 6 The largest 10 clusters of the keyword co-occurrence network

\begin{tabular}{|c|c|c|c|c|}
\hline Cluster & Size & Silhouette & $\begin{array}{l}\text { Mean } \\
\text { year }\end{array}$ & Label \\
\hline 0 & 23 & 0.831 & 2000 & Muscle strength change \\
\hline I & 23 & 0.856 & 2002 & Wheelchair propulsion \\
\hline 2 & 21 & 0.792 & 2002 & $\begin{array}{l}\text { Motor-incomplete tetraplegia } \\
\text { (or brain-machine interface) }\end{array}$ \\
\hline 3 & 21 & 0.978 & 2004 & $\begin{array}{l}\text { Voluntary wheel running } \\
\text { (or environmental enrichment) }\end{array}$ \\
\hline 4 & 20 & 0.770 & 1998 & $\begin{array}{l}\text { Spinal cord injury patient } \\
\text { (or urinary management) }\end{array}$ \\
\hline 5 & 19 & 0.902 & 1999 & Treadmill locomotion \\
\hline 6 & 19 & 0.896 & 1998 & $\mathrm{SCl}$ Rehab Project series \\
\hline 7 & 19 & 0.875 & 1999 & $\begin{array}{l}\text { Short form (or psychometric } \\
\text { characteristics) }\end{array}$ \\
\hline 8 & 15 & 0.873 & 1997 & $\begin{array}{l}\text { Current issue (and spasticity } \\
\text { management) }\end{array}$ \\
\hline 9 & 14 & 0.836 & 1998 & New muscle synergies \\
\hline
\end{tabular}

Abbreviation: $\mathrm{SCl}$ Rehab, Spinal Cord Injury Rehabilitation.

network, and this extensive scientific research cooperation shows that the research in this field has a certain degree of maturity. As mentioned previously, authors, institutions, and countries (or territories) with the highest published volume are the core forces in the global field of spinal cord injury rehabilitation and are the most powerful contributors to the research progress and development in this area. The authors, institutions, and countries (or territories) with leading betweenness centrality occupy the core position in global research cooperation and are the most important scientific research partners for global researchers in this field. Most of them have been able to maintain a high level of research output over the years and, to a certain extent, maintain the trend of increasing incidence year by year. If a researcher (institution, country, or territory) publishes significantly more papers in

Table 7 The largest 10 clusters of the term co-occurrence network

\begin{tabular}{lllll}
\hline Cluster & Size & Silhouette & $\begin{array}{l}\text { Mean } \\
\text { year }\end{array}$ & Label \\
\hline 0 & 56 & 0.837 & 2002 & $\begin{array}{l}\text { Spinal cord injury patient } \\
1\end{array}$ \\
\hline & 36 & 0.845 & 200 I & SCI Rehab Project \\
2 & 35 & 0.887 & 2000 & Longitudinal analysis \\
3 & 32 & 0.830 & 2002 & $\begin{array}{l}\text { Physical performance } \\
4\end{array}$ \\
29 & 0.882 & 200 I & $\begin{array}{l}\text { Spinal cord injury medicine } \\
\text { Health status (or life }\end{array}$ \\
5 & 22 & 0.838 & 1998 & $\begin{array}{l}\text { satisfaction) } \\
6\end{array}$ \\
& 22 & 0.898 & 1999 & $\begin{array}{l}\text { Training program } \\
\text { (or ambulation system) }\end{array}$ \\
7 & 21 & 0.769 & 1999 & Chronic pain \\
8 & 18 & 0.897 & 2003 & ICF core set \\
9 & 17 & 0.904 & 2002 & Young adult (or motor system) \\
\hline
\end{tabular}

Abbreviations: SCI Rehab, Spinal Cord Injury Rehabilitation; ICF, International Classification of Functioning, Disability and Health. several years, then a burst is considered to exist. The burst of researchers (institutions, countries, or territories) who have emerged in recent years and who are considered to be the most promising researchers gives us the reason to believe that they will make outstanding contributions to the field of spinal cord injury rehabilitation in the coming years, that they will make important breakthroughs, and that they are powerful competitors and important cooperators for research around the world. Understanding the research direction based on the understanding of the importance and status of collaborators is crucial to seek better cooperation in scientific research. In cluster network maps, observing the clusters in which researchers and research institutes are located can help us understand their main research direction to a certain extent.

Through this study, we determined that the top 10 researchers and research institutes with the largest number of published papers in the field of spinal cord injury rehabilitation over the past 20 years are from North America, Europe, and Oceania. Meanwhile, among the top 10 countries (or territories), except for Japan (9th) and China (10th), which are Asian countries, the rest are all located in North America, Europe, and Oceania. China is also the only developing country in the top 10 countries. This finding shows that countries in North America, Europe, and Oceania are outstanding in their research in this field. Meanwhile, for Asian countries, although Japan and China have performed well, they lack high-level research institutions and researchers; this will be one of the core areas for these countries to seek future breakthroughs. In recent years, the countries that have shown signs of burst mainly come from Asia and South America, whose progress will probably become an important force for promoting the research progress in this field in the future.

Knowledge foundation, knowledge structure, mainstream of research, hot spots, frontiers, and trends in this research area may be the most important issues for researchers, and largely help researchers understand the entire research field and select the research direction. Nodes (cited papers) in the co-citation network form the knowledge foundation. The cited papers with the highest citation frequency are important research foundations in the field of spinal cord injury rehabilitation. Among them, Reference for the 2011 revision of the International Standards for Neurological Classification of Spinal Cord Injury, ${ }^{22}$ which was published by Kirshblum et al in 2011, has been cited the most times and is the most important foundation. These important foundations should be familiar to every researcher in this field and are important avenues to help us attain an initial understanding of the key messages in this area. Cluster names (extracted from citing documents) of the co-citation network are considered 
the mainstream of research, whereas the largest of those clusters are considered to be the most important mainstream of research in the field of spinal cord injury rehabilitation in the past two decades. The name of the largest cluster is life satisfaction, containing 105 cited papers. Keywords and nominal terms co-occurrence networks represent research hot spots in this field, the frequency of occurrence, and the keywords with the highest betweenness centrality. The largest clusters in the keywords and nominal terms co-occurrence networks are the most important research hot spots in this field. Through this study, we determined that some of the most important hot spots in the field of spinal cord injury rehabilitation over the past two decades are life satisfaction, muscle strength, wheelchair training, walking, and gait, some special problems faced after spinal cord injury, such as urinary problems, pain, psychological problems, and spasticity, and some special treatments, such as treadmill training and wheel running, FES, and brain-computer interface. The research mainstream and hot spots are the core research directions and contents of this field in the past 20 years and are the main directions that researchers focus on. Researchers have made outstanding achievements and published a large number of articles in these areas. These directions are good choices for researchers, particularly for those strong research teams who are conducting research on spinal cord injury rehabilitation. However, selecting these directions may be risky for less-than-solid teams, given the massive investment by global researchers over the past two decades that makes these directions mature and makes important breakthroughs and innovations more difficult. For this situation, those research frontiers are better choices. In recent years, keywords that have presented burst, such as classification, exoskeleton, plasticity, and old adult, are the promising frontiers discovered through this study. We can also dynamically observe the research trends of different hot spots by using the time view map in the clustering network to better select research hot spots or frontiers as our own research direction. The study determined that the newest clustering in co-citation networks is gait rehabilitation (2009), psychometric characteristics (2008), and Spinal Cord Injury Rehabilitation Project (2008). The latest clustering in the keyword co-occurrence network is voluntary wheel running (or environmental enrichment) (2004), whereas the newest clustering in the nominal term co-occurrence network is psychometric characteristics (2009), ICF core set (2003), and spinal cord lesion (2003). We can further understand the knowledge structure of spinal cord injury rehabilitation research by analyzing the co-occurrence relationships of high-frequency keywords.

\section{Conclusion}

Research on the rehabilitation of spinal cord injury is a welldeveloped and promising research field. Research results have been increasing year by year in the past 20 years, but the growth trend has slowed down since 2011. Most studies are published in journals with IFs $<5$, and Archives of Physical Medicine and Rehabilitation, Spinal Cord, and Journal of Spinal Cord Injury and other journals are more interested in this type of research. The global research collaborations in this field have been close. Researchers, research institutes, and countries (or territories) from North America, Europe, and Oceania are the core research forces. Although Japan and China from Asia have relatively strong overall strength, they lack high-level researchers and research institutions. In recent years, several countries from Asia and South America have shown strong upward momentum and growth potential. Neurological classification, assessment, and treatment for walking problems are the most important research foundations in the field of spinal cord injury rehabilitation. Life satisfaction, American Spinal Injury Association score, ICF core set, young adult issues, muscle strength, wheelchair training, walking-related problems, urinary problems, pain, psychological problems, spasticity, treadmill training, aerobic exercise, cellular transplant, FES, and brain computer interface are the research mainstream and hot spots in this field. Classification, exoskeleton, plasticity, and old adult issues are likely to be potential future research directions.

\section{Data sharing statement}

The authors confirm that all data underlying the findings are fully available without restriction. All relevant data are within the paper.

\section{Acknowledgment}

This work was supported by the National Natural Science Foundation of China (grant no: 81261120563).

\section{Author contributions}

$\mathrm{MZ}$ contributed to overall study design. XL and NL contributed to methodology. XL, YL, and FL were involved in data curation and data acquisition. XL, YL, and FL contributed to formal analysis and interpretation of data. XL wrote the manuscript. All authors contributed toward data analysis, drafting and critically revising the paper, gave final approval of the version to be published, and agreed to be accountable for all aspects of the work.

\section{Disclosure}

The authors report no conflicts of interest in this work. 


\section{References}

1. van Asbeck FW, Post MW, Pangalila RF. An epidemiological description of spinal cord injuries in the Netherlands in 1994. Spinal Cord. 2000;38(7):420-424.

2. Warren S, Moore M, Johnson MS. Traumatic head and spinal cord injuries in Alaska (1991-1993). Alaska Med. 1995;37(1):11-19.

3. Dryden DM, Saunders LD, Rowe BH, et al. Utilization of health services following spinal cord injury: a 6-year follow-up study. Spinal Cord. 2004;42(9):513-525.

4. Wyndaelel M, Wyndaele JJ. Incidence, prevalence and epidemiology of spinal cord injury: what learns a worldwide literature survey? Spinal Cord. 2006;44(9):523-529.

5. McColl MA, Walker J, Stirling P, Wilkins R, Corey P. Expectations of life and health among spinal cord injured adults. Spinal Cord. 1997; 35(12):818-828.

6. Hills MW, Deane SA. Head injury and facial injury: is there an increased risk of cervical spine injury? J Trauma. 1993;34(4):549-554.

7. Levi AD, Casella G, Green BA, et al. Clinical outcomes using modest intravascular hypothermia after acute cervical spinal cord injury. Neurosurgery. 2010;66(4):670-677.

8. Chen C, Dubin R, Kim MC. Emerging trends and new developments in regenerative medicine: a scientometric update (2000-2014). Expert Opin Biol Ther. 2014;14(9):1295-1317.

9. Wang Q, Yang Y, Long C, Li H. A bibliometric analysis of research on the risk of engineering nanomaterials during 1999-2012. Sci Total Environ. 2014;473-474:483-489.

10. Li X, Dai J. Bridging the gap with functional collagen scaffolds: tuning endogenous neural stem cells for severe spinal cord injury repair. Biomater Sci. 2018;6(2):265-271.

11. Chen C. CiteSpace Manual [website on the Internet]. Available from: http://cluster.ischool.drexel.edu/ cchen/citespace. Accessed December 4, 2017.

12. Li JF, Zhang YH, Wang XS, Ho YS. Bibliometric analysis of atmospheric simulation trends in meteorology and atmospheric science journals. Croat Chem Acta. 2009;82(3):695-705.

13. Chen $\mathrm{C}$ science blog [website on the Internet]. Available from: http:// blog.sciencenet.cn/home.php?mod=space\&uid=496649. Accessed December 4, 2017.

14. Lee YC, Chen C, Tsai XT. Visualizing the knowledge domain of nanoparticle drug delivery technologies: a scientometric review. Appl Sci. 2016;6(1):11-17.

15. Small H. Co-citation in the scientific literature: a new measure of the relationship between two documents. J Am Soc Inf Sci Technol. 2010; 24(4):265-269.

16. Chen C. CiteSpace II: detecting and visualizing emerging trends and transient patterns in scientific literature. J Am Soc Inf Sci Technol. 2006;57(3):359-377.

17. Liu ZG, Yin YM, Liu WD, Dunford M. Visualizing the intellectual structure and evolution of innovation systems research: a bibliometric analysis. Scientometrics. 2015;103(1):135-158.

18. Chen C. Searching for intellectual turning points: progressive knowledge domain visualization. Proc Natl Acad Sci U S A. 2004;101(1): 5303-5310.

19. Wei FG, Grubesic TH, Bishop BW. Exploring the GIS knowledge domain using CiteSpace. Prof Geogr. 2015;67(3):347-384.

20. Betweenness centrality [website on the Internet]. Available from: https://enwikipediaorg/wiki/Betweenness_centrality. Accessed December 04, 2017.

21. Merigo JM, Casanovas M. Induced and heavy aggregation operators with distance measures. J Syst Eng Electron. 2010;21(3):10.

22. Kirshblum SC, Waring W, Biering-Sorensen F, et al. Reference for the 2011 revision of the International Standards for Neurological Classification of Spinal Cord Injury. J Spinal Cord Med. 2011;34(6):547-554.
23. Dobkin B, Apple D, Barbeau H, et al. Weight-supported treadmill vs over-ground training for walking after acute incomplete SCI. Neurology. 2006;66(4):484-493.

24. Wirz M, Zemon DH, Rupp R, et al. Effectiveness of automated locomotor training in patients with chronic incomplete spinal cord injury: a multicenter trial. Arch Phys Med Rehabil. 2005;86(4):672-680.

25. Maynard FM Jr, Bracken MB, Creasey G, et al. International standards for neurological and functional classification of spinal cord injury. American Spinal Injury Association. Spinal Cord. 1997;35(5):266-274.

26. Marino RJ, Barros T, Biering-Sorensen F, et al. International standards for neurological classification of spinal cord injury. J Spinal Cord Med. 2003;26(Suppl 1):50-56.

27. van Hedel HJ, Wirz M, Dietz V. Assessing walking ability in subjects with spinal cord injury: validity and reliability of 3 walking tests. Arch Phys Med Rehabil. 2005;86(2):190-196.

28. Hidler J, Nichols D, Pelliccio M, et al. Multicenter randomized clinical trial evaluating the effectiveness of the Lokomat in subacute stroke. Neurorehabil Neural Repair. 2009;23(1):5-13.

29. Fawcett JW, Curt A, Steeves JD, et al. Guidelines for the conduct of clinical trials for spinal cord injury as developed by the ICCP panel: spontaneous recovery after spinal cord injury and statistical power needed for therapeutic clinical trials. Spinal Cord. 2007;45(3):190-205.

30. Francisco GE, Yozbatiran N, Berliner J, et al. Robot-assisted training of arm and hand movement shows functional improvements for incomplete cervical spinal cord injury. Am J Phys Med Rehabil. 2017; 96(10 Suppl 1):171-177.

31. Jayaraman A, Burt S, Rymer WZ. Use of lower-limb robotics to enhance practice and participation in individuals with neurological conditions. Pediatr Phys Ther. 2017;29(Suppl 3):48-56.

32. Huggins JE, Moinuddin AA, Chiodo AE, Wren PA. What would brain-computer interface users want: opinions and priorities of potential users with spinal cord injury. Arch Phys Med Rehabil. 2015; 96(3 Suppl):38-45.

33. Thomschewski A, Höller Y, Höller P, Leis S, Trinka E. High amplitude EEG motor potential during repetitive foot movement: possible use and challenges for futuristic BCIs that restore mobility after spinal cord injury. Front Neurosci. 2017;(11):362.

34. Tidoni E, Gergondet P, Fusco G, Kheddar A, Aglioti SM. The role of audio-visual feedback in a thought-based control of a humanoid robot: a BCI study in healthy and spinal cord injured people. IEEE Trans Neural Syst Rehabil Eng. 2017;25(6):772-781.

35. Zhang R, Wang Q, Li K, et al. A BCI-based environmental control system for patients with severe spinal cord injuries. IEEE Trans Biomed Eng. 2017;64(8):1959-1971.

36. Yoshida N, Hashimoto Y, Shikota M, Ota T. Relief of neuropathic pain after spinal cord injury by brain-computer interface training. Spinal Cord Ser Cases. 2016;2:16021.

37. Fonseca AFB, Scheffer JP, Giraldi-Guimarães A, Coelho BP, Medina RM, Oliveira ALA. Comparison among bone marrow mesenchymal stem and mononuclear cells to promote functional recovery after spinal cord injury in rabbits. Acta Cir Bras. 2017;32(12):1026-1035.

38. Hosseini SM, Sani M, Haider KH, et al. Concomitant use of mesenchymal stem cells and neural stem cells for treatment of spinal cord injury: a combo cell therapy approach. Neurosci Lett. 2018;668:138-146.

39. Lankford KL, Arroyo EJ, Nazimek K, Bryniarski K, Askenase PW, Kocsis JD. Intravenously delivered mesenchymal stem cell-derived exosomes target M2-type macrophages in the injured spinal cord. PLoS One. 2018;13(1):e0190358.

40. Zhang F. Structure-function evaluation of stem cell therapies for spinal cord injury. Curr Stem Cell Res Ther. 2018;13(3):202-214.

41. World Health Organization. International Classification of Functioning, Disability and Health (ICF). Geneva: World Health Organization; 2001. 


\section{Publish your work in this journal}

Therapeutics and Clinical Risk Management is an international, peerreviewed journal of clinical therapeutics and risk management, focusing on concise rapid reporting of clinical studies in all therapeutic areas, outcomes, safety, and programs for the effective, safe, and sustained use of medicines. This journal is indexed on PubMed Central, CAS,

EMBase, Scopus and the Elsevier Bibliographic databases. The manuscript management system is completely online and includes a very quick and fair peer-review system, which is all easy to use. Visit http://www.dovepress.com/testimonials.php to read real quotes from published authors.

Submit your manuscript here: http://www.dovepress.com/therapeutics-and-clinical-risk-management-journal 